\title{
IMAGES IN CLINICAL PRACTICE
}

\section{NAIL CHANGES IN A CHILD WITH ACUTE LYMPHOBLASTIC LEUKEMIA}

\author{
Govind Kendre, Shruti Mantri, Sunil Hilalpure, Suraj Goyanka, Leo Prince, Murlidharan C. \\ Department of Clinical Hematology, Seth G.S. Medical College, KEM Hospital, Parel, Mumbai, India.
}

\begin{abstract}
A 15-year-old girl, diagnosed with B cell acute lymphoblastic leukemia, receiving the BFM-90 protocol presented with transverse white and bluish black bands on the nails of all fingers and toes (Figure 1). She had received daunorubicin, vincristine, cyclophosphamide, and methotrexate as a part of her chemotherapy protocol. These nail changes were observed after the completion of the consolidation phase of the BFM protocol.
\end{abstract}

Figure 1. Nail changes

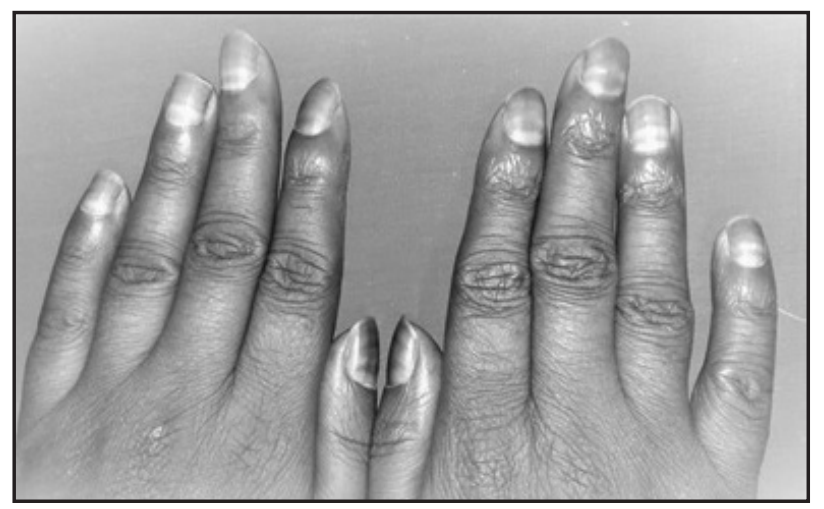

What is the cause of her nail discoloration?

The cause of her nail discoloration is chemotherapyinduced nail discoloration. The side-effects of anticancer therapy can vary from life-threatening cytopenias to the benign cutaneous changes. The mucocutaneous effects of chemotherapy are very much distressing to patients receiving chemotherapy. Chemotherapy-associated nail abnormalities result from toxicity to nail bed, periungual tissues or digital blood vessels. ${ }^{1}$ The chemotherapy drugs can cause various nail changes such as nail dystrophy; nail discoloration (chromonychia), leukonychia, Beau's lines and onycholysis. ${ }^{2}$ The main chemotherapy agents causing these nail changes are daunorubicin, vincristine, cyclophosphamide, methotrexate, etoposide, bleomycin, dacarbazine, hydroxyurea and doxorubicin. ${ }^{1,2,3}$ In our patient, due to exposure to various chemotherapy drugs simultaneously, the exact culprit drug could not be pointed out. The various nail changes can be seen in many medical diseases such as chronic kidney disease, myocardial infarction, metallic exposure, immune hemolytic anemia, systemic lupus erythematosus and Hodgkin's disease. ${ }^{2,4}$ Chemotherapy-induced nail

\section{CONTACT Govind Kendre}

Email: govindken143@gmail.com

Address for Correspondence: Dr. Govind Kendre, Department of Clinical Haematology, Seth G.S.

Medical College, KEM Hospital, Parel, Mumbai.

\author{
ARTICLE HISTORY \\ Received 4 February 2019 \\ Accepted 21 February 2019

\section{KEYWORDS} \\ Chemotherapy, daunorubicin, \\ methotrexate, vincristine, \\ cyclophosphamide, nail, \\ chromonychia, leukonychia
}

changes although asymptomatic can provoke anxiety in already stressed patients, sometimes leading to poor compliance and discontinuation of chemotherapy. They do not require treatment and resolve after completion of chemotherapy. ${ }^{1}$ In our patient also the nail changes resolved after chemotherapy was completed.

\section{Acknowledgment}

We thank Dr. Chandrakala S (HOD clinical hematology) and Dr. Farah Jijina for their valuable inputs.

\section{Compliance with Ethical Standards \\ Funding: None \\ Conflict of Interest: None}

\section{References :}

1. Dasanu CA, Alexandrescu DT, Wiernik PH. Recognizing nail and skin changes associated with chemotherapy. Resident and staff physician. 2006. p. 52.

2. Hinds G, Thomas VD. Malignancy and cancer treatmentrelated hair and nail changes. Dermatol Clin. 2008;26:5968.

3. Dasanu CA, Vaillant JG, Alexandrescu DT. Distinct patterns of chromonychia, Beau's lines and melanoderma seen with vincristine, adriamycin, dexamethasone for multiple myeloma. Dermatol Online J. 2006;12:10.

4. Lambertenghi Deliliers G, Monni P. The irreplaceable image: Nail transverse white bands induced by antileukemic chemotherapy. Haematologica. 2001;86:333. 